\title{
Türkiye'nin Farklı İllerinde Yetiştirilen "Hayward" (Actinidia deliciosa Planch) Kivi Çeşidinin Serbest Aroma Bileşiklerinin Belirlenmesi
}

\begin{abstract}
Kemal ŞEN ${ }^{1 *}$
ÖZ

Bu çalışmada, ülkemizin farklı illerinde yetiştirilen (Mersin, Ordu, Samsun ve Yalova) Hayward kivi çeşidinin serbest aroma bileşiklerinin belirlenmesi amaçlanmıştır. Aroma maddelerinin ekstraksiyonu sıvı-sıv1 ekstraksiyon yöntemiyle gerçekleştirilmiştir. Kivilerdeki aroma maddelerinin tanımlanmasında GC-MS, miktarlarının hesaplanmasında ise GC-FID sistemleri kullanılmıştır. Ordu ve Samsun illerinden temin edilen kivi örneklerinde 86 adet, Mersin ilinden temin edilen kivi örneğinde 80 adet ve Yalova ilinden temin edilen kivi örneğinde 72 adet aroma bileşiği tanımlanmıştır. Samsun ve Ordu illerinden temin edilen kivi örnekleri alkol, ester ve lakton bileşimi bakımından diğerlerine göre daha baskın karakterde olduğu tespit edilmiş̧ir. Mersin ve Yalova illerinden temin edilen kivi örneklerinin ise hem terpen hem de uçucu fenol bileşikleri bakımından diğer illerden ayrıldığı saptanmıştır. Hem aroma bileşimleri hem de aroma profil analizleri bakımından değerlendirildiğinde, Ordu ve Samsun ìllerinden temin edilen kivi örneklerinin kalite bakımından diğer illere göre daha iyi özelliklere sahip olduğu belirlenmiştir.
\end{abstract}

Anahtar Kelimeler: Hayward, kivi, GC-MS-FID, uçucu bileşikler

\section{Determination of Free Aroma Compounds of "Hayward" (Actinidia deliciosa Planch) Kiwi Fruit Variety Grown in Different Provinces of Turkey}

\begin{abstract}
In this study, it was aimed to determine the aroma compounds of the Hayward kiwi fruit variety grown in different provinces in Turkey (Mersin, Ordu, Samsun, and Yalova). The extraction of aroma compounds was carried out by the liquid-liquid extraction method Aroma compounds were identified and quantified using the GC-MS-FID. 86 aroma compounds were identified in kiwi fruit samples obtained from Ordu and Samsun provinces, 80 in kiwi fruit samples obtained from the Mersin province, and 72 aroma compounds in kiwi fruit samples obtained from the Yalova province. Kiwi fruit samples obtained from Samsun and Ordu provinces were found to be more dominant than the others in terms of alcohol, ester, and lactone composition. Kiwi fruit samples obtained from Mersin and Yalova provinces differ from other regions in terms of both terpene and volatile phenol compounds. When evaluated in terms of both aroma composition and aroma profile analysis, it was determined that the kiwi samples obtained from Ordu and Samsun provinces had better characteristics than other provinces in terms of quality.
\end{abstract}

Keywords: Hayward, kiwi, GC-FID, GC-MS, volatile compounds

ORCID ID (Yazar sirasina göre)

0000-0003-0781-6814

\footnotetext{
Yayın Kuruluna Geliş Tarihi: 19.05.2021

Kabul Tarihi: 09.06.2021

${ }^{1}$ Nevşehir Hacı Bektaş Veli Üniversitesi, Mühendislik Mimarlık Fakültesi, Gıda Mühendisliği

Bölümü, Nevșehir, Türkiye

*E-posta: kemalsen@ nevsehir.edu.tr
} 


\section{Türkiye'nin Farklı İllerinde Yetiştirilen "Hayward" (Actinidia deliciosa Planch) Kivi Çeşidinin Serbest Aroma Bileşiklerinin Belirlenmesi}

\section{Giriş}

Kivi, birim alandan yüksek gelir getirmesi, vitamin ve mineral içeriğinin zenginliği yanında düşük kalorili olması yönüyle, son y1llarda üretimi ve tüketimi hızla artan meyve türlerinden birisidir (Günay, 2009).

Anavatanı Çin olan kivi, 1900'lü yılların başlarında Yeni Zelanda'ya götürülmüştür. Yaklaşık 50 yıl önce Yeni Zelanda'da üretimi artmaya başlamış, daha sonra İtalya, Şili, Fransa, Yunanistan ve Japonya gibi ülkelerde yayılma alanı bulmuştur (Anonim, 2002). 2019 yılında dünya kivi üretimi 4,348,011 ton iken, Türkiye üretimi 63,098 ton olarak gerçekleşmiştir (Fao, 2021). 2020 yılında ise ülkemizin toplam kivi üretimi 73,745 tona çıkmıştır (Tuik, 2021).

Ülkemizde üretilen kiviler büyük oranda sofralık olarak değerlendirilmekte, bunun yanında az da olsa reçel-marmelat, meyve suyu üretimlerinde ve pastacilık sektöründe kullanılmaktadır. Ayrıca, ülkemiz koşullarında yetiştirilen bu meyvenin son y1llardaki üretim hacmindeki artışa bağlı olarak, katma değeri daha yüksek farklı ürünlerin üretiminde değerlendirilebilmesi yönünde bir potansiyel de oluşmaktadır. Ancak bunun için meyvenin kalite karakteristiklerinin belirlenmesi gerekmektedir (Kambur ve Gündoğdu, 2020).

Tüketici açısından kalite denildiğinde ilk akla gelen görünüş, renk, tat ve aroma gibi duyusal özelliklerdir. Bu özellikler içerisinde aromanın önemli bir yeri vardır (Şen, 2021). Bu maddeler genel olarak burun ve geniz yoluyla algilanır ve lezzet üzerinde etkili olurlar. Meyvelerde ve işlenmiş ürünlerde genellikle düşük miktarlarda bulunan bu uçucu bileşiklerin konsantrasyonunu etkileyen başlıca faktörler çeşit, iklim koşulları, olgunlaşma, bölge ve ișleme tekniğidir (RiuAumatell ve ark., 2004). Aroma maddeleri, meyvelerde diğer bileşenlere göre çok düşük miktarlarda bulunmalarına rağmen meyvenin kendine özgü duyusal özelliğini belirlerler. Meyvelerde aroma maddeleri; aldehitler, yüksek alkoller, ketonlar, esterler, laktonlar ve terpenler gibi çeşitli kompleks gruplardan oluşur (RiuAumatell ve ark., 2004) ve bu maddeler GC veya GC-MS gibi enstrümantal cihazlarla kalitatif ve kantitatif olarak hassas bir şekilde belirlenebilir.
Her meyvenin toprak ve iklim isteği aynı değildir. $\mathrm{Bu}$ nedenle bir meyve çeşidinin erişebileceği en uygun kimyasal bileşim yetiştirildiği yörenin toprak yapısı ve iklim koşulları ile yakından ilgilidir (Amerine ve ark., 1972; Jackson, 2000). Bu durum kivi meyvesi için de geçerlidir. Ülkemizde kivi meyvesi Akdeniz, Karadeniz ve Marmara bölgelerinde yetiştirilmekle birlikte bu meyvedeki aroma bileşikleri üzerine kapsamlı bir araştırmaya rastlanmamıştır. Oysa ki, ülkemizde kivi yetiştiriciliği değişik coğrafi bölgelere dağılmış durumdadır ve bu bölgeler arasında toprak ve iklim koşulları bakımından önemli farklılıklar vardır. Bu nedenle kivi meyvesinin yetiştirildiği bölgeleri konu alan sistemli araştırmalara ihtiyaç duyulmaktadır.

$\mathrm{Bu}$ çalışmada, ülkemizin farklı illerinde yetiştirilen (Mersin, Ordu, Samsun ve Yalova) Hayward kivi çeşidinin aroma bileşiklerinin belirlenmesi amaçlanmıştır.

\section{Materyal ve Yöntem \\ Materyal}

Araştırmada kullanılan kivi materyalleri meyvenin deriminin başladığ 1 Kasım-2015 döneminde özel soğutmalı $20 \mathrm{~L}$ hacimli termos kasalarla Mersin, Ordu, Samsun ve Yalova illerinden Nevşehir Hacı Bektaş Veli Üniversitesi Gıda Mühendisliği bölümüne getirilmiş ve analizlerin gerçekleştirildiği süre içerisinde $4^{\circ} \mathrm{C}^{\prime} \mathrm{de}$ depolanmıştır. Kiviler optimum olgunlukta, en az 10 ağaçtan ve her ağacın farklı bölgelerinden 10'ar $\mathrm{kg}$ olacak şekilde toplanmıştır.

\section{Yöntem}

\section{Genel Bileșim Analizleri}

Genel bileşim analizleri olarak kivi örneklerinde; suda çözünür kuru madde (SÇKM), toplam şeker (Cemeroğlu, 2013), toplam asit, pH tayinleri (Tob, 1983) yapılmıştır.

\section{Aroma bileşiklerinin ekstraksiyonu}

Aroma bileşiklerinin ekstraksiyonu için 26000 devir/dk hızla çalışan bir mekanik parçalayıcıda püre haline getirilmiş $100 \mathrm{~g}$ kivi kullanılmıştır. Homojenize edilen $100 \mathrm{~g}$ püre $500 \mathrm{ml}$ 'lik erlen içerisine alınmış ve üzerine $40 \mathrm{ml}$ diklorometan ve iç standart olarak $41.57 \mu \mathrm{g}$ 4-nonanol ilave edilmiştir. Erlendeki karışım azot gazı altında, 4- 


\section{Türkiye'nin Farklı İllerinde Yetiştirilen "Hayward" (Actinidia deliciosa Planch) Kivi Çeşidinin Serbest Aroma Bileşiklerinin Belirlenmesi}

$5 \quad{ }^{\circ} C^{\prime}$ de, manyetik karıştırıcıda 30 dakika karıştırılarak, ekstraksiyon işlemi gerçekleştirilmiştir (Blanch ve ark.,1991; Priser ve ark.,1997; Şen, 2021). Bu işlem sonucunda iki faza ayrılan erlen içeriğinden aroma maddelerini içeren çözücü fazı ayrılmış ve bu faz "Vigreux" damitma kolonunda $40{ }^{\circ} \mathrm{C}^{\prime} \mathrm{de} 1 \mathrm{ml}$ kalincaya kadar konsantre edilmiştir. Konsantre halde elde edilen ekstrakt doğrudan GC-MS-FID sistemine enjekte edilerek serbest aroma maddeleri belirlenmiştir. Ekstraksiyonlar üç tekerrürlü yapılmıştır.

\section{GC-MS-FID koșulları}

Aroma maddelerinin tanımlanması ve miktarlarının belirlenmesi "Agilent 6890N" marka alev iyonlaşma dedektörlü (FID) gaz kromatografisi ve buna bağlı "Agilent 5975B VL MSD" kütle spektrometresinde es zamanlı olarak gerçekleştirilmiştir. Bu tür sistemlerde kolon çıkışı özel bir ayırıcı (Dean switch) yardımıyla eşit olarak ikiye ayrılmakta; birinci kısım FID'ye, ikinci kısım ise MSD'ye gitmektedir. Böylece aynı zaman dilimi içerisinde hem miktar tayini ve hem de tanımlama işlemi yapılabilmektedir.

Aroma maddelerinin ayrımı DB-WAX kapiler kolon $(30 \mathrm{~m} \times 0.25 \mathrm{~mm} \times 0.25 \mu \mathrm{m})$ kullanılarak gerçekleştirilmiştir. Gaz kromatografisinde enjeksiyon bloğu sıcaklığı $220{ }^{\circ} C^{\prime}$ ye, FID'nin bulunduğu dedektör bloğu sicaklığ 1 ise 250 ${ }^{\circ} \mathrm{C}$ 'ye ayarlanmıştır. Kolon firının sıcaklığı, 40 ${ }^{\circ} \mathrm{C}$ 'de 4 dakika beklemeden sonra, dakikada $2{ }^{\circ} \mathrm{C}$ arttırılarak $220{ }^{\circ} \mathrm{C}$ 'ye ve daha sonra dakikada $3{ }^{\circ} \mathrm{C}$ arttırılarak $245{ }^{\circ} \mathrm{C}$ 'ye çıkarılmıș ve bu sicaklıkta 20 dakika sabit kalacak şekilde programlanmıştır. Cihaza enjekte edilen ekstrakt miktarı $2 \mu$ l'dir. Taşıyıcı gaz olarak $\mathrm{He}$ kullanılmıştır. Helyumun akış hızı 2.2 ml/dakika olarak ayarlanmıştır.

Aroma maddelerinin tanisinda yukarida belirtilen gaz kromatografisine bağl1 "Agilent 5975B VL MSD" marka kütle spektrometresi kullanılmıştır. Kütle spektrometresinin iyonlaşma enerjisi $70 \mathrm{eV}$, iyon kaynağ $\mathrm{s}_{\text {c.caklığ }}$ $250^{\circ} \mathrm{C}$, kuadrupol sicaklığ $120{ }^{\circ} \mathrm{C}$ olarak ayarlanmış ve 1 saniye aralıklarla 29-350 kütle/yük $(\mathrm{m} / \mathrm{e})$ arasında tarama yapılmıștır (Schneider ve ark., 2001; Topi, 2020; Sevindik ve ark., 2020). Piklerin tanıs1, kütle spektrometresi cihazında bulunan kütüphanelerden (Wiley 7.0, NIST 98 ve Flavor $2 \mathrm{~L}$ ), aroma maddelerinin saf standartlarından ve Kovats indeks değerlerinden yararlanılarak gerçekleştirilmiştir. Tanımlanan her bir aroma bileşiğinin Kovats indeks değeri C7-C36 arasındaki tüm alkanları içeren bir çözeltinin yukarıda belirtilen kolon ve gaz kromatografisi koşullarında, enjeksiyonu gerçekleştirilerek belirlenmiştir (Van Den Hool ve Kratz, 1963). Piklerin tanısından sonra aroma maddelerinin konsantrasyonları iç standart yöntemiyle hesaplanmıştır (Sönmezdağ ve ark., 2018).

\section{Aroma Profil Analizi}

Kivi örneklerinin aroma profil analizi, önceden hazırlanmış $10 \mathrm{~cm}$ 'lik bir skala yardımıyla eğitimli 7 panelist (29 yaş ortalaması ve 4 kadın, 3 erkek) tarafindan gerçekleștirilmiștir (Uçkun ve Selli, 2017; Kesen, 2020; Şen, 2021). Aroma profil analizleri için panelistlerin eğitimi, her biri 1 saat süren 7 ayrı oturumda farklı kokuları temsil eden standart çözeltileri koklamaları sağlanarak gerçekleştirilmiştir. Koklama solüsyonlarında; meyvemsi kokular için etil hekzanoat ve etil dekanoat, çiçeksi kokular için sitronelal, sitral ve jeraniol, baharatımsı kokular için $\alpha$-pinen, L-mentol, tropik kokular için bütil pentanoat, $\gamma$-nonalakton ve etil oktanoat, bitkisel yeşil kokular için hekzanal, (E)-2hekzenal ve (Z)-3-hekzenol, ilaç benzeri kimyasal kokular için ise naftalinden oluşan standart bileşikler kullanılmıștır. Eğitimde kullanılan her bir bileșiğin sudaki koku eşik değerleri dikkate alınarak koklama solüsyonları hazırlanmıştır. Sonraki aşamada, her bir kivi örneğinden $10 \mathrm{~g}$ alınarak $25 \mathrm{ml}$ 'lik kahverengi kapaklı cam şişelere konulmuştur. Her bir kivi örneğinden diklorometan ile elde edilen ekstraktlar ise özel kağıt koklama çubuklarına (SARL H. Granger-Veyron, Fransa) emdirilmiş ve çözücünün buharlaşması için 1 dakika beklenmiştir. $\mathrm{Bu}$ koklama çubukları, kahverengi kapaklı dört farklı 25 ml'lik cam şişeye konulmuştur. Daha sonra her bir kivi örneği kendisini temsil eden ekstrakt ile eşleştirilerek panelistlere sunulmuştur. Panelistlerden örnekleri ve ekstraktlarını karşılaştırmaları istenmiştir.

\section{İstatistiksel analizler}




\section{Türkiye'nin Farklı İllerinde Yetiştirilen "Hayward" (A. Deliciosa Planch) Kivi Çeşidinin Serbest Aroma Bileşiklerinin Belirlenmesi}

Araştırmadan elde edilen sonuçların istatistiksel olarak değerlendirilmesinde XLStat (2020) (Addinsoft, NewYork, NY, USA) paket programı kullanılmıştır. Konsantrasyonlar ve standart sapmalar (SD), MS Office kullanilarak Excel yazılımı ile belirlenmiştir. Farklılıkları değerlendirmek için varyans analizi ve Duncan'in çoklu karşılaştırma test yöntemleri kullanılmıştır. $\mathrm{p}<0,05$ 'lik farklar anlamlı kabul edilmiştir. Ek olarak, bir temel bileşen analizi (PCA) de gerçekleştirilmiştir. Gözlemler ve değişkenler bakımından veri matrisi, aroma bileşiklerinin kimyasal sınıflarından ve kivi numunelerinden oluşturulmuştur.

\section{Bulgular ve Tartışma \\ Kivilerin Genel Bileşim Özellikleri}

Ülkemizin farklı illerinden elde edilen kivilerin genel bileşim özellikleri Çizelge 1'de verilmiştir. Çizelge 1'de görüldüğü gibi kivi örneklerinde $\mathrm{pH}$ değerleri 3.3-3.6, toplam asitlik değerleri 1.22-1.49 g/100 g, suda çözünür kuru madde miktarları (SÇKM) \% 10.9-13.1 ve toplam şeker miktarları 9.66-11.53 $\mathrm{g} / 100 \mathrm{~g}$ aralığında değişmiştir. Altuntaş ve ark. (2009), "Hayward" kivi çeşidinde yaptıkları çalışmada yeme olgunluğu döneminde meyvede $\mathrm{pH}$ değerinin 3.3, toplam asitlik miktarının $1.73 \mathrm{~g} / 100 \mathrm{~g}$ olarak bulunduğunu ve SÇKM değerlerinin ise ortalama \% 14.1 ile \% 17.0 arasında değiştiğini bildirmişlerdir. Cangi ve Karadeniz (1999), Ordu ilinin değişik rakımlarında yetiştirilen "Hayward" kivi çeşidinde yeme olgunluğu döneminde SÇKM değerlerinin $\% \quad 14.1$ ile $\% 17.0$ arasında değiştiğini bildirmişlerdir. Uslu (2006), yapmış olduğu çalışmada "Hayward" kivi çeşidinde titre edilebilir asit miktarının 1.1-1.3 g/100 g arasında değiștiğini bildirmiștir. Lintas ve ark. (1991), yapmış oldukları bir çalışmada "Hayward" kivi çeşidinde toplam şeker miktarının 10.51-11.92 g/100 g arasında değiştiğini bildirmişlerdir. Görüldüğü üzere sonuçlar literatürle uyum içesindedir.

Çizelge 1. Kivilerin genel bileşim özellikleri*

\begin{tabular}{lcccc}
\hline Genel Özellikleri & Mersin & Ordu & Samsun & Yalova \\
\hline pH & $3.3 \pm 0.03$ & $3.6 \pm 0.02$ & $3.6 \pm 0.02$ & $3.5 \pm 0.01$ \\
Toplam asitlik (Sitrik asit cinsinden g/100 g) & $1.41^{\mathrm{a}} \pm 0.02$ & $1.49^{\mathrm{a}} \pm 0.04$ & $1.46^{\mathrm{a}} \pm 0.05$ & $1.22^{\mathrm{b}} \pm 0.03$ \\
\% SÇKM & $10.9^{\mathrm{b}} \pm 0.15$ & $13.3^{\mathrm{a}} \pm 0.38$ & $12.8^{\mathrm{a}} \pm 0.21$ & $11.5^{\mathrm{b}} \pm 0.49$ \\
Toplam Şeker (g/100 g) & $9.66^{\mathrm{b}} \pm 0.22$ & $11.53^{\mathrm{a}} \pm 0.54$ & $11.02^{\mathrm{a}} \pm 0.72$ & $10.39^{\mathrm{b}} \pm 0.31$ \\
\hline
\end{tabular}

* Aynı satırda değişik harflerle gösterilen değerler arasındaki fark istatistiksel olarak önemlidir $(\mathrm{p}<0.05)$.

\section{Kivi Örneklerinin Aroma Bileșimi}

Çizelge 2'de kivi örneklerinin aroma bileşimi verilmiştir. Kivi örnekleri üzerinde yapılan aroma bileşikleri analizi sonucunda;

Mersin ilinden temin edilen kivi örneğinde 80 adet (20 adet aldehit ve keton, 9 adet alkol, 15 adet ester, 11 adet terpen, 10 adet lakton, 4 adet uçucu fenol ve 11 adet uçucu asit) aroma bileşiği,

Ordu ilinden temin edilen kivi örneğinde 86 adet $(21$ adet aldehit ve keton bileşiği, 11 adet alkol, 19 adet ester, 10 adet terpen, 10 adet lakton, 4 adet uçucu fenol ve 11 adet uçucu asit) aroma bileşiği,

Samsun ilinden temin edilen kivi örneğinde 86 adet (21 adet aldehit ve keton, 11 adet alkol, 19 adet ester, 10 adet terpen, 10 adet lakton, 4 adet uçucu fenol ve 11 adet uçucu asit) aroma bileşiği ve
Yalova ilinden temin edilen kivi örneğinde 72 adet (18 adet aldehit ve keton, 9 adet alkol, 10 adet ester, 11 adet terpen, 9 adet lakton, 4 adet uçucu fenol ve 11 adet uçucu asit) aroma bileşiği tanımlanmıştır.

Aroma maddelerinin toplam miktarları bakımından Ordu ilinden temin edilen kivi örneği $11691.8 \mu \mathrm{g} / \mathrm{kg}$ ile ilk sırada yer alırken, bu örneği $10110.3 \mu \mathrm{g} / \mathrm{kg}$ ile Samsun, 6537.7 $\mu \mathrm{g} / \mathrm{kg}$ ile Yalova ve $5515.7 \mu \mathrm{g} / \mathrm{kg}$ ile Mersin ilinden temin edilen kivi örnekleri izlemiştir.

Kivi örneklerinin aldehit ve keton bileşikleri sayısı bakımından oldukça zengin bir bileşime sahip olduğu görülmektedir. Toplam miktarları açısından bir değerlendirme yapıldığında Ordu $(2250.8 \mu \mathrm{g} / \mathrm{kg})$, Yalova $(2024.2 \mu \mathrm{g} / \mathrm{kg}) \quad \mathrm{ve}$ Samsun $(1951.7 \mu \mathrm{g} / \mathrm{kg})$ illerinden elde edilen 
kiviler birbirlerine yakın değerler verirken, en düşük aldehit ve keton miktarı Mersin ilinden elde edilen kivi örneğinde $(1053,7 \mu \mathrm{g} / \mathrm{kg})$ bulunmuştur. Bu bileşikler içerisinde sadece 3metil-bütanal, 2,3-pentanedion, Hekzanal, (Z)2-pentenal, (E)-2-pentenal, (E)-2-Hekzenal, (Z)-2-heptenal, 4-hidroksi-4-metil-2-pentanon, 1-hidroksi-2-bütanon, (E)-2-dekenal, (E,Z)-2,4dekadienal ve (E,E)-2,4-dekadienal miktarlarının toplamı, toplam aldehit keton bileşikleri miktarının \%74-98'ini oluşturmaktadır. Kivi üzerine yapılmış olan bir çalışmada bu bileşiklerin kivinin karakteristik kokusu üzerinde etkili olduğu bildirilmiştir. Bu çalışmada, hekzanal yeşil ot, çim kokusu ile, (E)-2-pentenal meyvemsi, çilek kokusu ile, (E)2-hekzenal meyvemsi, çilek ve vişne kokusu ile, (E,E)-2,4-heptadienal portakal benzeri yağımsı koku ile karakterize edilmiştir (Jordan ve ark., 2002). Yine miktar bakımından öne çıkan aldehitler ise (E,Z)-2,4-dekadienal ve (E,E)-2,4-dekadienal olarak görülmektedir. Bu bileşiklerden (E,Z)-2,4-dekadienal sardunya kokusu ile karakterize edilirken, (E,E)-2,4dekadienal ise portakal benzeri yeşil, tatlımsı bir koku ile karakterize edilmektedir (Gomez ve Ledbetter, 1997).

Toplam alkol miktarları bakımından bir değerlendirme yapıldığında, en yüksek alkol miktarı $824.1 \mu \mathrm{g} / \mathrm{kg}$ ile Ordu ilinden temin edilen kivi örneğinde tespit edilmiş, bunu 481.4 $\mu \mathrm{g} / \mathrm{kg}$ ile Samsun, $310.9 \mu \mathrm{g} / \mathrm{kg}$ Yalova ve 305,4 $\mu \mathrm{g} / \mathrm{kg}$ ile Mersin ilinden temin edilen kivi örnekleri izlemiştir. Alkol grubu bileşikler içerisinde miktar bakımından 2-metil-3-büten-2ol, 1-penten-3-ol ve 3-penten-2-ol bileşikleri ön plana çıkmaktadır. Bu bileşikler toplam alkol bileşikleri miktarının \%23-87'sini oluşturmaktadır. Bunlardan 3-penten-2-ol daha önce kivi ile ilgili yapılan bir çalışmada, kivinin aroma aktif bileşiklerinden biri olduğu ve bitkisel, yeşil yanmış kauçuk kokusu ile karakterize edildiği bildirilmiştir (Jordan ve ark., 2002).

Çoğunluğu meyvemsi, şekerimsi kokulardan sorumlu olan ester bileşiklerinin meyvelerin aroması üzerinde önemli bir rolü vardır Komes ve ark., 2005). Mersin, Ordu, Samsun ve Yalova illerinden temin edilen kivilerin toplam ester miktarları sırasıyla $489.0 \mu \mathrm{g} / \mathrm{kg}, 6212.7 \mu \mathrm{g} / \mathrm{kg}$, $5111.5 \mu \mathrm{g} / \mathrm{kg}$ ve $478.6 \mu \mathrm{g} / \mathrm{kg}$ olarak belirlenmiştir. Belirlenen ester bileşikleri içerisinde metil bütanoat, etil valerat, etil bütanoat, etil hekzanoat, etil-3-hidrokisi bütanoat, metil benzoat ve etil benzoat bileşikleri, toplam ester miktarının \%95-98'ini oluşturmaktadır. Bunlardan etil bütanoat (meyvemsi, çilek kokusu), metil benzoat (marul, karpuz benzeri koku) ve etil benzoatın (papatya, kereviz benzeri koku) kivinin karakteristik aromas1 üzerinde etkili olduğu bildirilmiştir (Jordan ve ark., 2002). Wang ve ark. (2011) yaptıkları bir çalışmada Hayward çeşidi olgun kivilerde toplam ester miktarının $49.9 \mu \mathrm{g} / \mathrm{kg}$ ile $80.2 \mu \mathrm{g} / \mathrm{kg}$ arasında değiştiğini, aşırı olgun kivilerde ise ester miktarının $27178.6 \mu \mathrm{g} / \mathrm{kg}$ 'a kadar çıktığını bildirmişlerdir. 


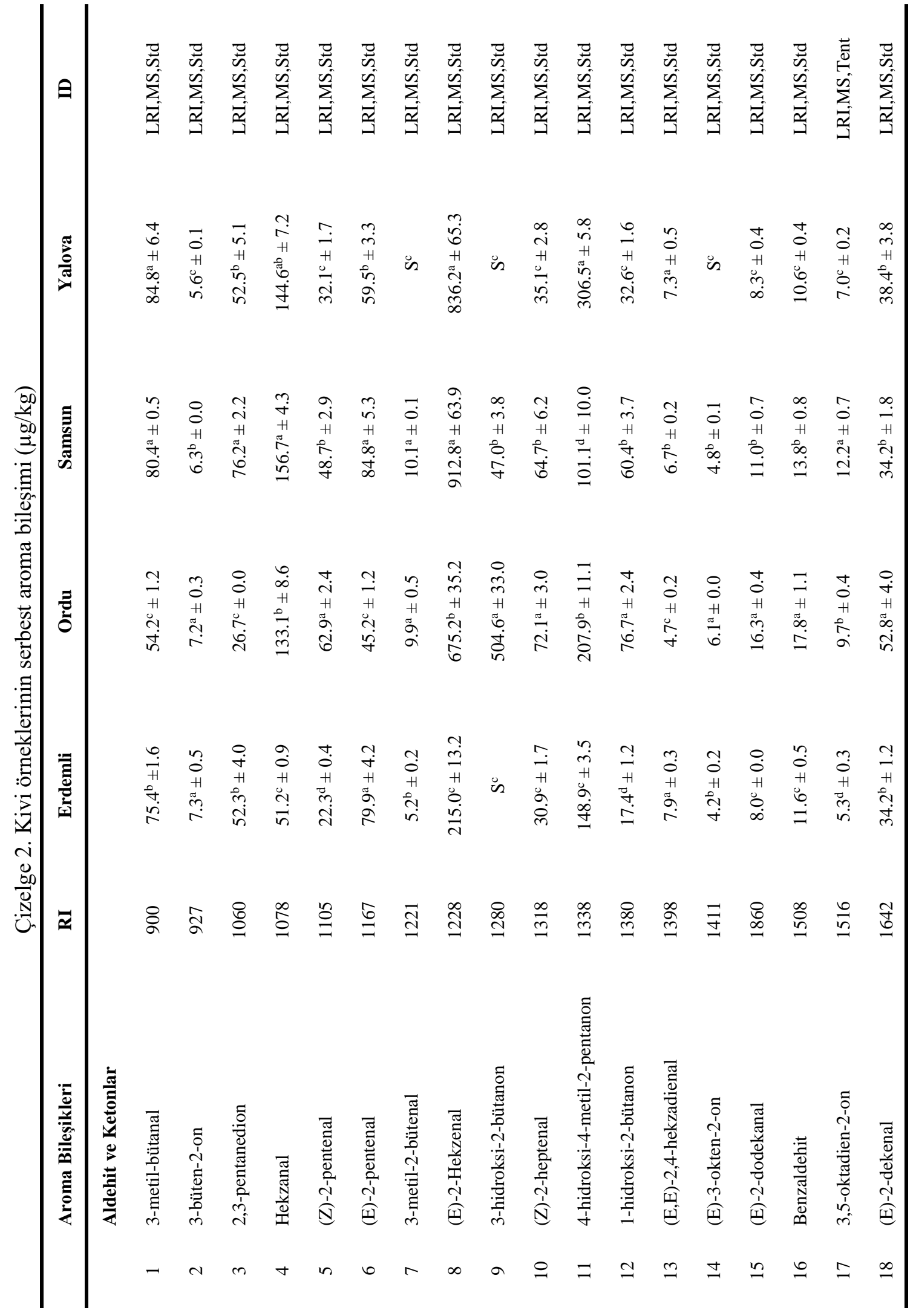




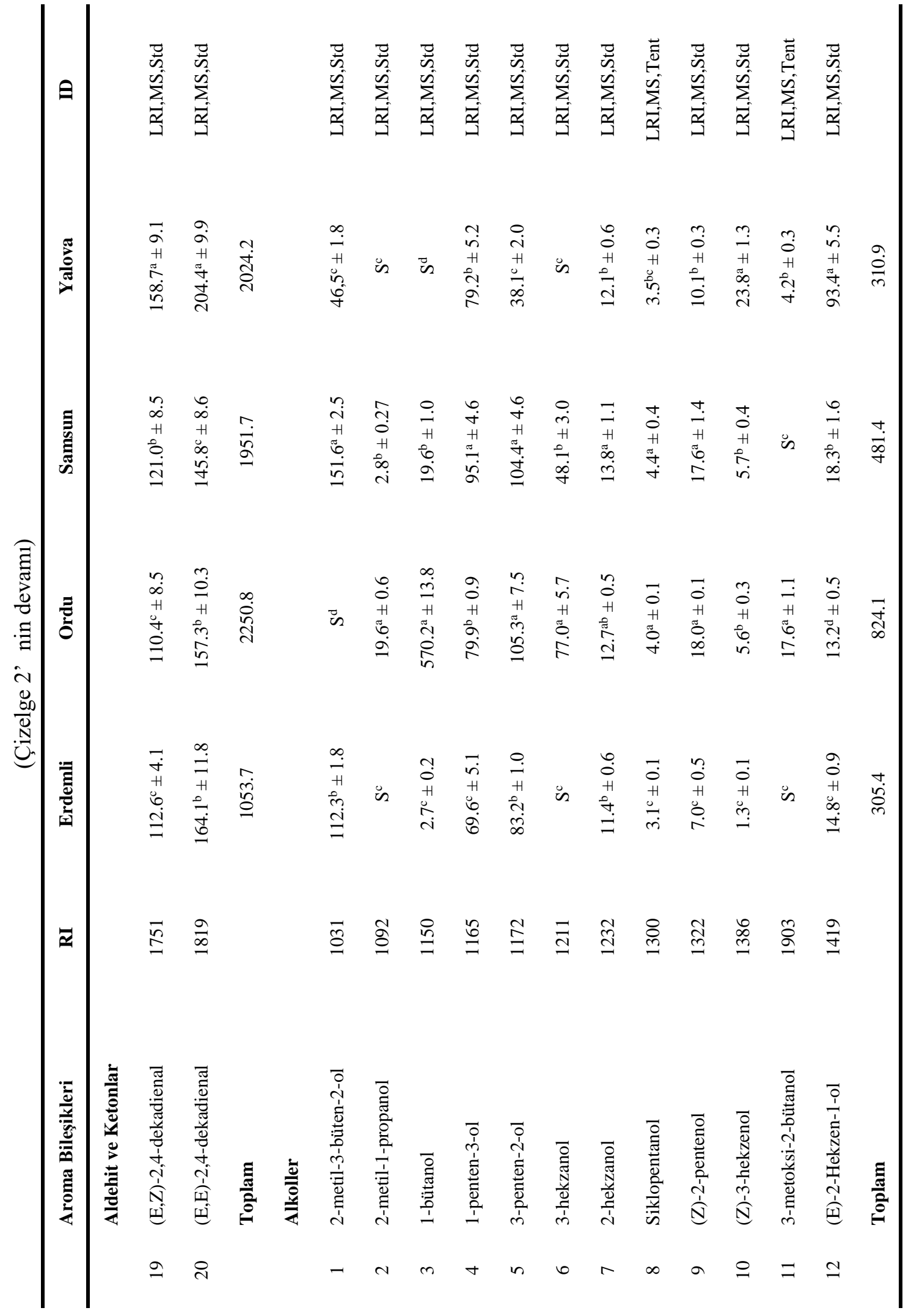




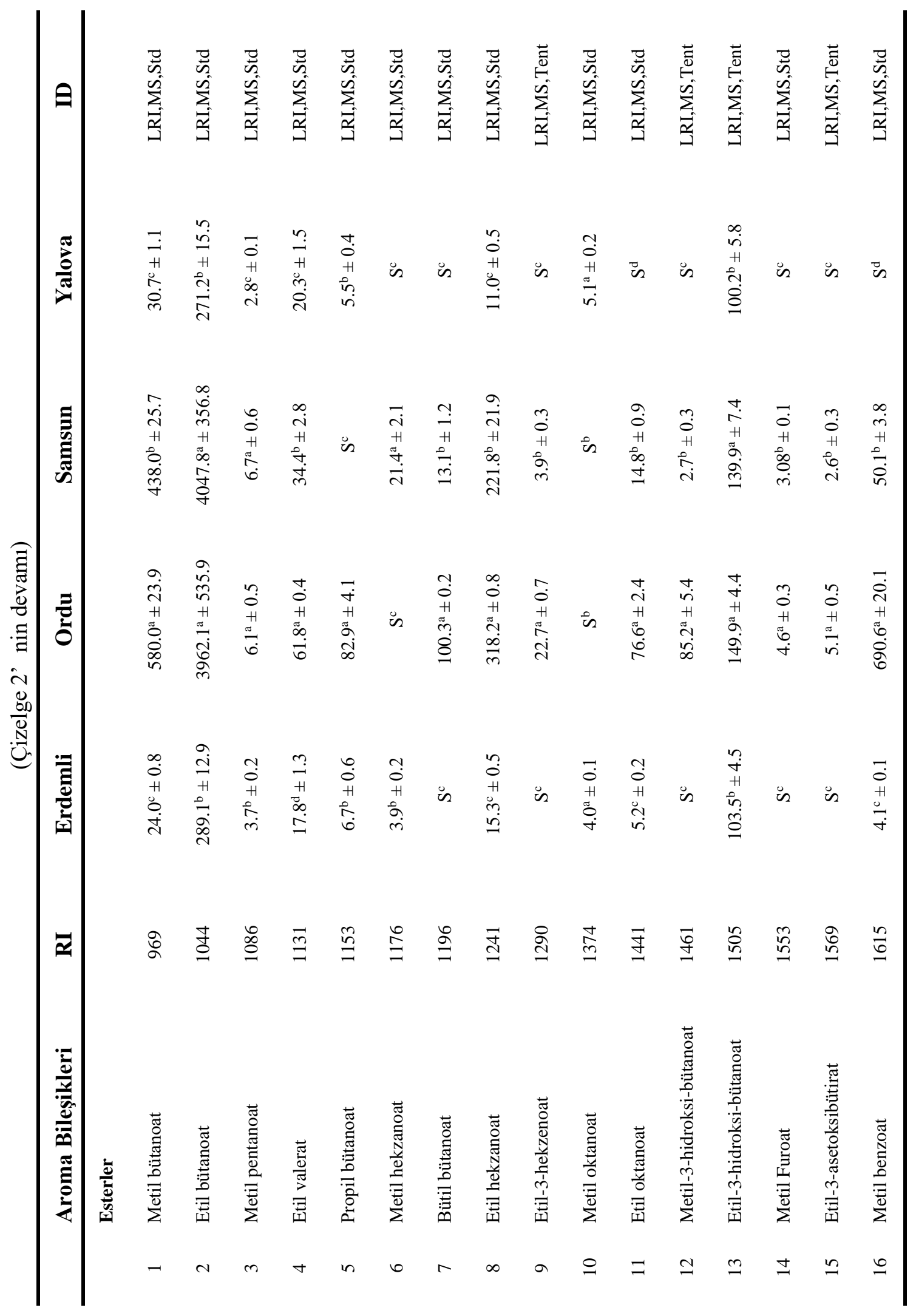




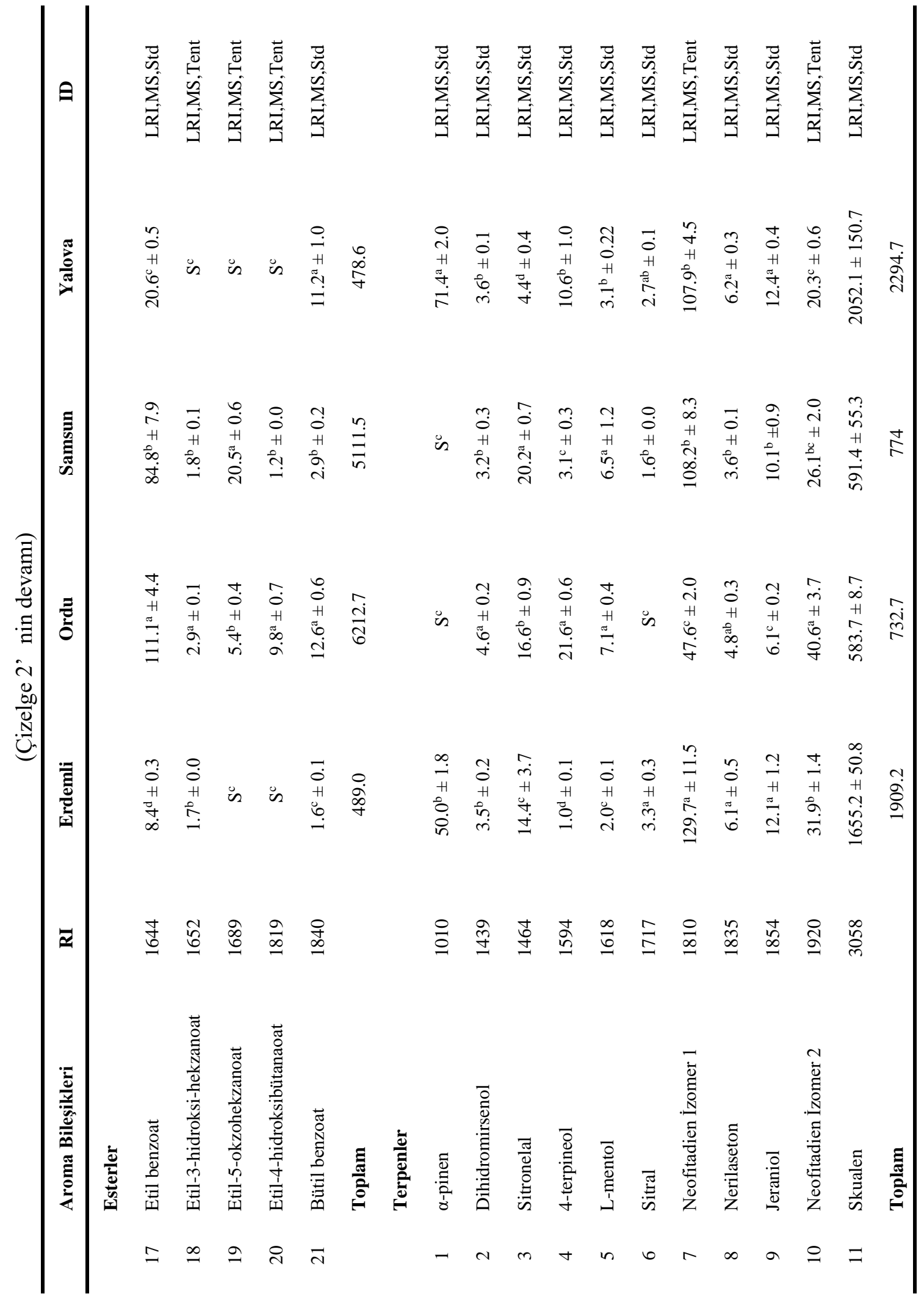




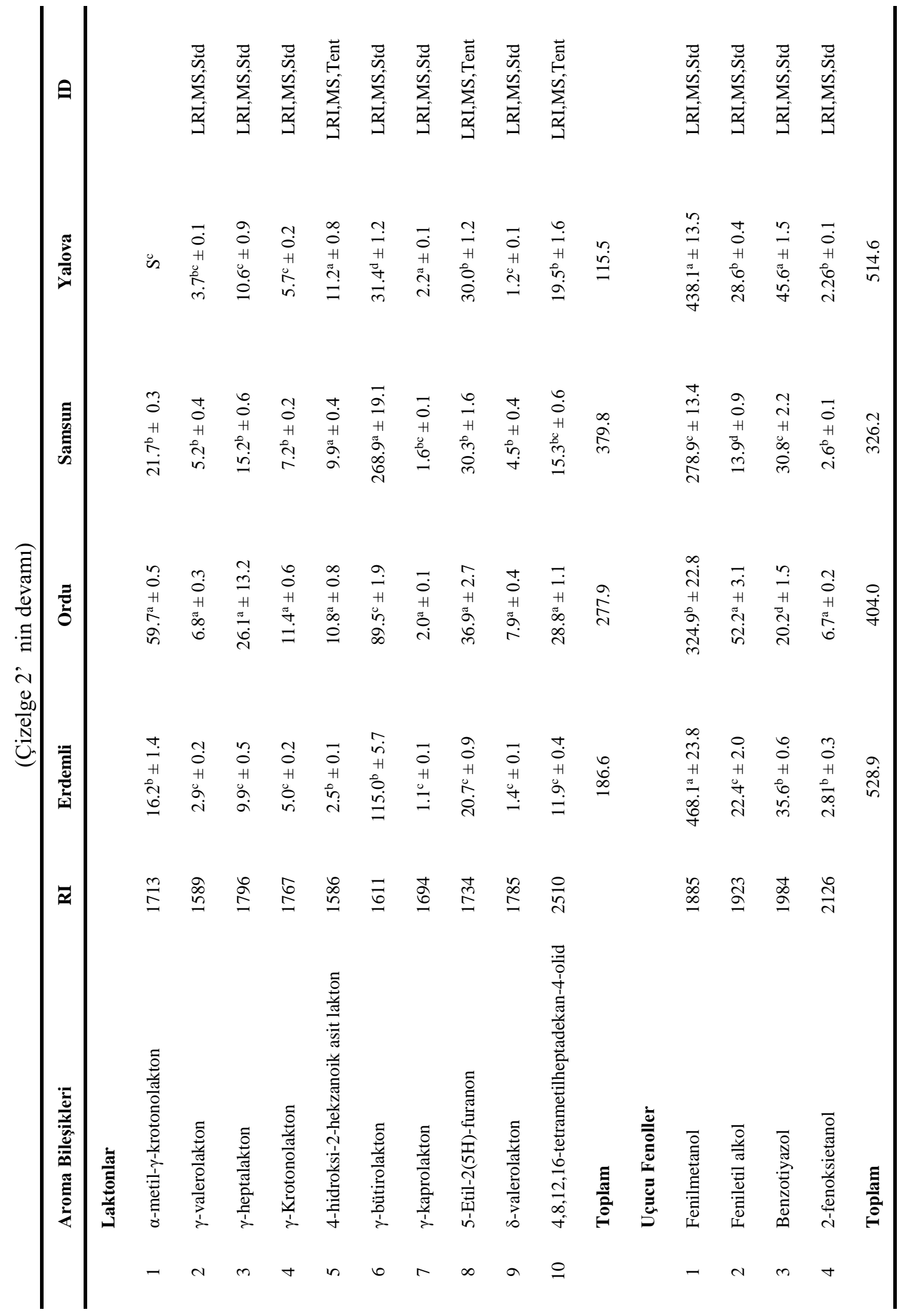




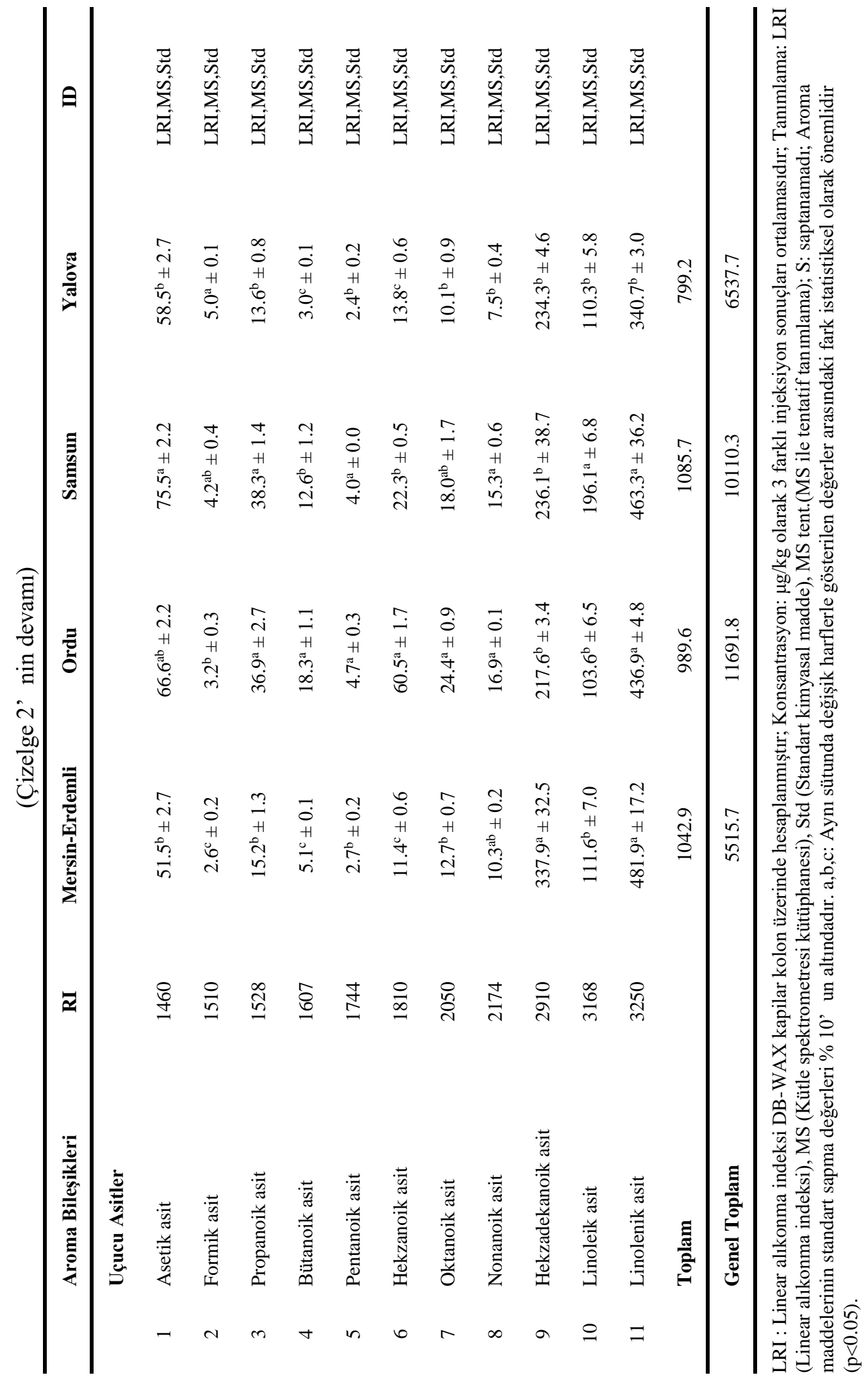




\section{Türkiye'nin Farklı İllerinde Yetiştirilen "Hayward" (A. Deliciosa Planch) Kivi Çeşidinin Serbest Aroma Bileşiklerinin Belirlenmesi}

Genel olarak çiçeksi ve bazıları meyvemsi kokulardan sorumlu terpen grubu bileşikler meyvelerin önemli aroma maddeleri arasında yer almaktadır (Gomez ve ark., 1993; Gomez ve Ledbetter, 1997; Riu-Aumatell ve ark., 2004; Riu-Aumatell ve ark., 2005; Aubert ve Chanforan, 2007). Toplam terpen bileşikleri miktarı bakımından $2294.7 \mu \mathrm{g} / \mathrm{kg}$ ile Yalova illerinden temin edilen kiviler ilk sirada yer alırken, bunu $1909.2 \mu \mathrm{g} / \mathrm{kg}$ ile Mersin, 774.0 $\mu \mathrm{g} / \mathrm{kg}$ ile Samsun ve $732.7 \mu \mathrm{g} / \mathrm{kg}$ ile Ordu ilinden temin edilen kivi örnekleri izlemiştir. $\mathrm{Bu}$ bileşiklerden $\alpha$-pinen, sitronelal, jeraniol, neofitadien izomer 1 , neofitadien izomer 2 ve skualen bileşiklerinin toplamı terpen bileșiklerinin \%95-99'unu olușturmaktadır. Yapılan bir çalışmada, Yeni Zelenda'da yetiştirilen Hayward çeşidi kivi meyvesinin olgunlaşma süresince terpen bileşikleri miktarının $23.7 \mu \mathrm{g} / \mathrm{kg}$ 'dan $42.1 \mu \mathrm{g} / \mathrm{kg}$ 'a kadar çıktığı bildirilmiştir (Wang ve ark., 2011). Bu çalışmaya göre bir değerlendirme yapılırsa, ülkemizde yetiştirilen kivi meyvelerinin terpen bileşikleri bakımından oldukça zengin olduğu söylenebilir.

Yapılan birçok araştırmada lakton grubu bileşiklerin, meyve aromasından sorumlu bileşikler olduğu ve genel olarak tropik kokularla karakterize edildiği bildirilmektedir (Chairote ve ark., 1981; Guichard ve Souty, 1988). Lakton bileşikleri bakımından 379.8 $\mu \mathrm{g} / \mathrm{kg}$ ile Samsun ilinden temin edilen kivi örneği ilk sırada yer alırken, bunu $277.9 \mu \mathrm{g} / \mathrm{kg}$ ile Ordu, $186.6 \mu \mathrm{g} / \mathrm{kg}$ ile Mersin ve $115.5 \mu \mathrm{g} / \mathrm{kg}$ ile Yalova ilinden temin edilen kivi örnekleri takip etmiştir. Kiviler lakton bileşiği çeşitliği bakımından oldukça zengin bulunmuştur. $\mathrm{Bu}$ bileşiklerden $\quad \alpha$-metil- $\gamma$-krotonolakton, $\quad \gamma$ heptalakton, $\quad \gamma$-bütirolakton, $\quad$ 5-Etil-2 $(5 \mathrm{H})$ furanon ve 4,8,12,16-tetrametilheptadekan-4olid miktar bakımından toplam lakton miktarının \%63-90'1nı oluşturmaktadır ve bu bileşikler içerisinde $\gamma$-bütirolakton, toplam lakton bileşiğinin \%27-71'ini oluşturmaktadır. Yapılan bazı çalıșmalarda, kivi meyvesinde lakton bileşikleri içerisinde yalnızca $\gamma$-bütirolakton bileşiğinin tespit edildiği bildirilmiştir (Wan ve ark., 1999; Jordan ve ark., 2002). Buna göre ülkemizde yetiştirilen kivi meyveleri hem lakton bileşiklerinin çeşitliliği hem de bu bileşiklerin miktarları bakımından oldukça baskın özellikler taşımaktadır.

Toplam uçucu fenol bileşikleri bakımından $528.9 \mu \mathrm{g} / \mathrm{kg}$ ile Mersin ilinden elde edilen kivi örneği ilk sırada yer alırken, bunu $514.6 \mu \mathrm{g} / \mathrm{kg}$ ile Yalova, $404 \mu \mathrm{g} / \mathrm{kg}$ ile Ordu ve $326.2 \mu \mathrm{g} / \mathrm{kg}$ ile Samsun ilinden temin edilen kivi örnekleri izlemiştir. Bu bileşikler içerisinde fenilmetanol ve 2 -fenil etanol, toplam fenol bileşikleri miktarının \% 90-93'ünü oluşturmaktadır. Bunlardan fenilmetanol tatlımsı, çiçeksi koku ile karakterize edilirken, 2-fenil etanol kivilerde çiçeksi, baharatımsı, gül kokusu ile karakterize edilmiştir (Jordan ve ark., 2002; Fanaro ve ark., 2012). Başka bir çalışmada, Hayward çeşidi kivi meyvesinde uçucu fenol bileşiklerinden fenil metanol, 2-fenil etanol, gayakol ve 2,4-Di-tertbütil-fenol bileşikleri tespit edilmiştir. $\mathrm{Bu}$ bileşiklerin miktarları sırasıyla, $1.55 \mu \mathrm{g} / \mathrm{kg}, 1.19$ $\mu \mathrm{g} / \mathrm{kg}, \quad 1.43 \mu \mathrm{g} / \mathrm{kg}$ ve $0.42 \mu \mathrm{g} / \mathrm{kg}$ olarak belirlenmiştir (Zhao ve ark., 2021). Görüldüğü üzere, ülkemizde yetiştirilen kivi meyveleri uçucu fenol bileşikleri bakımından dikkate değer miktarlarda bir bileşime sahiptir.

Yüksek algılanma eşiklerinden dolayı uçucu asitlerin aromaya doğrudan katkısı olmamasına rağmen, bu bileşiklerin $\gamma$ - ve $\delta$ - laktonların ve esterlerin oluşumunda rol oynadığını bilinmektedir (Tang ve Jenings, 1967). Uçucu asitler bakımından tüm illerden temin edilen kivilerde toplamda 12 adet uçucu asit tespit edilmiştir. En yüksek uçucu asit miktarı Samsun ilinden temin edilen kivi örneğinde (1085.7 $\mu \mathrm{g} / \mathrm{kg})$ saptanmış, bunu Mersin $(1042.9 \mu \mathrm{g} / \mathrm{kg})$, Ordu $(989.6 \mu \mathrm{g} / \mathrm{kg})$ ve Yalova $(799.2 \mu \mathrm{g} / \mathrm{kg})$ illeri izlemiştir. Zhao ve ark. (2021) yapmış oldukları bir çalışmada Hayward çeşidi kivi meyvesinde hekzanoik asit, heptanoik asit ve oktanoik asit olmak üzere toplamda 3 adet uçucu asit bileşiği belirlemişler ve bunların toplam miktarlarının $\quad 3.71 \quad \mu \mathrm{g} / \mathrm{kg} \quad$ olduğunu bildirmişlerdir. Ülkemizde yetiştirilen kivi meyvelerinin uçucu asit bileşimi bakımından zenginliği dikkate değer bir durumdur. Kivi örneklerinin uçucu asitler bakımından zengin bir içeriğe sahip olması, kivi örneklerindeki lakton ve ester bileşiklerindeki çeşitliği açıklamaktadır.

Kivi örneklerinde aroma bileşikleri grupları 


\section{Türkiye'nin Farklı İllerinde Yetiştirilen "Hayward" (Actinidia deliciosa Planch) Kivi Çeşidinin Serbest Aroma Bileşiklerinin Belirlenmesi}

açısından bir sınıflandırma yapmak amacıyla, elde edilen veriler üzerinden bir model oluşturularak Temel Bileșen Analizi (PCA) gerçekleştirilmiştir. Şekil 1'de görüldüğü üzere, PCA modeli toplam varyansin \%94.28'ini açıklayan iki temel bileşenle oluşturulmuştur (F1: \%73.81; F2: \%20.47). Buna göre Samsun ve Ordu illerinden elde edilen kivi örnekleri koordinat düzleminin săg tarafında, Mersin ve Yalova illerinden elde edilen kivi numuneleri ise koordinat düzleminin sol tarafında konumlanmıştır.

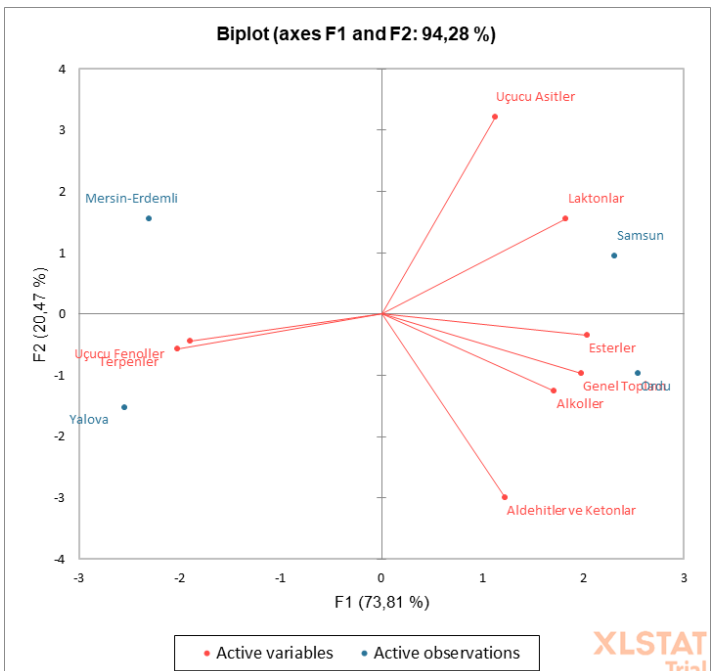

Şekil 1. Kivi örneklerinin serbest aroma bileşimi açısından temel bileşen analizi ile karşılaştırılması

Grafikten de görülebileceği gibi, aroma gruplarının koordinat düzlemindeki konumları ile kivi örneklerinin konumları arasındaki korelasyon oldukça önemli bulunmuştur. Şekil l'e göre, Samsun ve Ordu illerinden temin edilen kivi örnekleri alkoller, esterler ve laktonlar bakımından baskın bir karaktere sahiptir. Laktonlar ve uçucu asitler açısından, Samsun ilinden elde edilen kivi örneklerinin iyi bir profile sahip olduğu, Ordu ilinde temin edilen kivi örneklerinin ise, ester, alkol, aldehit ve keton gruplarının baskınlığ bakımından daha fazla ön plana çıktığı görülmektedir. Diğer taraftan, Mersin ve Yalova illerinden temin edilen kivi örneklerinin hem terpen hem de uçucu fenol bileşikleri bakımından diğer illerden ayrıldığı görülmektedir.

\section{Aroma Profil Analizi}

Ülkemizin farklı illerinden elde edilen kivilerin ve bunlardan elde edilen ekstraktların aroma profil analizlerinin sonuçları Şekil 2'de verilmiştir.

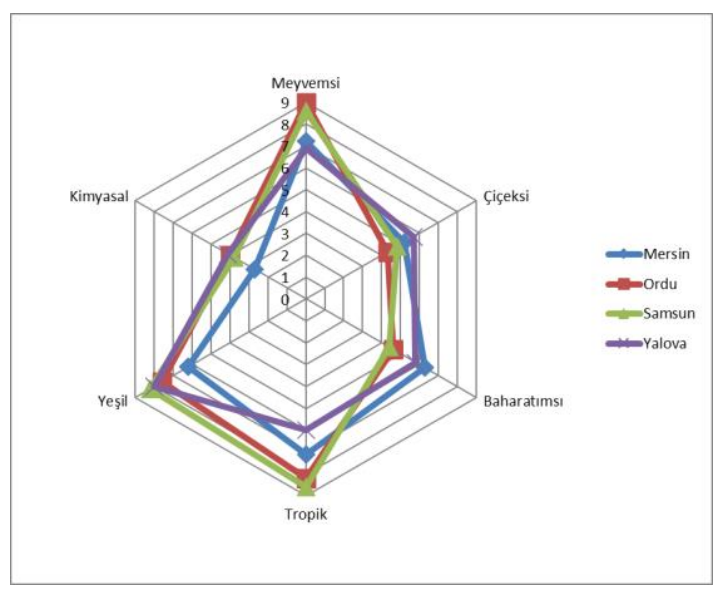

Şekil 2. Kivi örneklerinin aroma profil analizi diyagramı

Yukarıda verilen diyagram incelendiğinde, kivi örnekleri içerisinde Ordu ilinden temin edilen kivi örneği, meyvemsi özellikler açısından en yüksek puanı almış ve bunu sırasıyla Samsun, Mersin ve Yalova illerinden temin edilen kivi örnekleri takip etmiştir. Çiçeksi özellikler bakımından en yüksek puanı Yalova alırken en düşük puanı Ordu ilinden temin edilen kiviler almıştır. Baharatımsı özellikler bakımından ise en yüksek puanı Mersin ilinden temin edilen kiviler alırken, bunu Yalova, Ordu ve Samsun illerinden temin elden kiviler izlemiştir. Tropik koku özellikleri bakımından Samsun ilinden temin edilen kiviler en fazla öne çıkan örnek olup, bu özellikler bakımından en zayı örnek Yalova ilinden temin edilen kiviler olmuştur. Yeşil özellik kavramı genel olarak çim, saman, ot, odun kokusunu temel almaktadır. $\mathrm{Bu}$ kapsamda bu özellikler bakımından en fazla Samsun ilinden temin edilen kivi örnekleri ön plana çıkmıștır. Bunu Yalova, Ordu ve Mersin illerinden temin edilen kivi örnekleri takip etmiştir. Kimyasal özellikler ise örneklerde genel olarak plastik, kauçuk, ilaç kokusu gibi kokuların olup olmadığını göstermek amacıyla kullanılan bir terimdir. $\mathrm{Bu}$ bakımdan değerlendirildiğinde bu özellik herhangi bir ilde 


\section{Türkiye'nin Farklı İllerinde Yetiştirilen "Hayward" (A. Deliciosa Planch) Kivi Çeşidinin Serbest Aroma Bileşiklerinin Belirlenmesi}

ön plana çıtı̆̆g söylenemez. Bununla birlikte en yüksek puanı Yalova ilinden temin edilen kivi örneği almıştır.

Genel olarak bakıldığında tüm profil özellikleri bakımından meyveler arasında önemli bir fark bulunamamıştır. Ancak meyvemsi ve tropik özellikler bakımından Ordu ve Samsun illerinden temin edilen kivi örneklerinin daha çok beğeni topladığı söylenebilir.

\section{Sonuç ve Öneriler}

$\mathrm{Bu}$ çalışmada, ülkemizin farklı illerinde yetiştirilen (Yalova, Ordu, Muğla ve Mersin) Hayward kivi çeşidinin aroma bileşikleri belirlenmiştir. Genel olarak kivi örneklerinin aroma bileşiklerinin büyük bölümünü aldehit ve ketonlar ile ester bileşiklerinin oluşturduğu tespit edilmiştir. Tespit edilen aroma bileşikleri illere göre farklılık göstermekle birlikte, Mersin ve Yalova illerinden temin edilen kivilerin istatistiksel olarak birbirlerine yakın bir profil sergiledikleri görülmüş, benzer durumun Samsun ve Ordu illerinden elde edilen kiviler için de geçerli olduğu tespit edilmiştir. Genel olarak bir değerlendirme yapılacak olursa, Hayward çeşidi kivilerin illere göre aroma bileşiklerinin değişiklik gösterdiği ancak hem sayısal veriler hem de duyusal değerlendirmeler dikkate alındığında Samsun ve Ordu illerinde üretilen Hayward çeşidi kivilerin duyusal özellikler bakımından daha fazla ön plana çıktığı söylenebilir. Ancak bu durumun toplam yağış, güneşlenme gibi iklimsel verilerle ve toprak özellikleri harmanlanarak birlikte düşünülmesi ve gelecekte yapılacak çalışmaların bu yönde yeniden şekillendirilmesinde yarar olduğu düşünülmektedir.

\section{Teşekkür}

$\mathrm{Bu}$ araştırma, Nevşehir Hacı Bektaş Veli Üniversitesi Bilimsel Araştırma Projeleri (BAP) Koordinasyon Birimi tarafından desteklemiştir. (Proje No: NEÜBAP15/2F20).

\section{Kaynaklar}

Altuntaş, E., Cangi, R., Kaya, C., Dilmaç, M., Saraçoğlu, O. (2009) Hayward kivi çeşidinin hasat ve yeme olumu dönemlerindeki bazı fiziksel, mekanik ve kimyasal özelliklerinin belirlenmesi. III.
Ulusal Üzümsü Meyveler Sempozyumu, 293-301.

Amerine, M.A. Berg, H.W. Crues, W.V. (1972)

The technology of winemaking. The AVI

Publishing Campnay, Inc, Vesport, Connecticut.

Aubert, C., Chanforan, C. (2007) Postharvest changes in physicochemical properties and volatile constituents of apricot (Prunus armeniaca L.). Characterization of 28 cultivars, J. Agric. Food Chem., 55:30743082. https://doi.org/10.1021/jf063476w

Blanch, G.P., Reglero, G., Herraiz, M., Tabera, J. (1991) A comparison of different extraction methods for the volatile components of grape juice, $J$. Chromatographic Sci., 29:11-15. https://doi.org/10.1093/chromsci/29.1.11

Cangi, R., Karadeniz, T. (1999) Ordu'da değişik rakımlarda yetiştirilen hayward (actinidia deliciosa) kivi çeşidinde verim ve meyve özellikleri üzerine araştırmalar. Karadeniz Bölgesi Tarım Sempozyumu 4-5 Ocak 1999. Bildiriler. Ondokuz Mayıs Üniversitesi Ziraat Fakültesi, Samsun. 425432.

Cemeroğlu, B. (2013) Gıda analizleri. Bizim Grup Basımevi, Ankara.

Chairote, G., Rodriguez, F., Crouzet, J. (1981) Characterization of additional volatile flavor components of apricot, J. Food Sci., 46:1898-1906. https://doi.org/10.1111/j.13652621.1981.tb04514.x

FAO,2021. Dünya Gida ve Tarım örgütü. http://www.fao.org/faostat/en/\#data/QC.

Fanaro, G.B., Duarte, R.C., Santillo, A.G., Pinto E Silva, M.E.M., Purgatto, E., Villavicencio, A.L.C.H. (2012) Evaluation of $\gamma$-radiation on oolong tea odor volatiles. Rad. Phys. and Chem., 81(8):1152-1156. https://doi.org/10.1016/j.radphyschem.201 1.11 .061

Gomez, E., Ledbetter, C.A., Hartsell, P.L. (1993) Volatile compounds in apricot, 


\section{Türkiye'nin Farklı İllerinde Yetiştirilen "Hayward" (Actinidia deliciosa Planch) Kivi Çeşidinin Serbest Aroma Bileşiklerinin Belirlenmesi}

plum, and their interspecific hybrids, $J$. Agric. Food Chem., 41:1669-1676. https://doi.org/10.1021/jf00034a029

Gomez, E., Ledbetter, C.A. (1997) Development of volatile compounds during fruit maturation: characterization of apricot and plum x apricot hybrids. J. Sci. Food Agric., 74:541-546.

https://doi.org/10.1002/(SICI)1097-

0010(199708)74:4\%3C541::AID-

JSFA851\%3E3.0.CO;2-D

Guichard, E., Souty, M. (1988) Comparison of the relative quantities of aroma compounds found in fresh apricot (Prunus armeniaca) from six varieties. Z. Lebensm. -Unters. Forsch., 186:301-307. https://doi.org/10.1007/BF01027031

Günay, K. (2009) Ordu ekolojisinde yetiştirilen "hayward" (a. deliciosa planch) kivi çeşidinde önemli meyve kalite özelliklerinin rakım ve yöneye göre değişimi. (Yüksek Lisans Tezi), Ordu Üniv. Fen Bil. Enst., Ordu.

Jackson, R.S. (2000) Wine science. Acedemic Press, Elsevier Science, USA.

Jordan, M.J., Margaria, C.A., Shaw, P.E., Kevin L. Goodner, K.L. (2002) Aroma active components in aqueous kiwi fruit essence and kiwi fruit puree by gc-ms and multidimensional GC/GC-O. J. Agric. Food Chem., 50:5386-5390. https://doi.org/10.1021/jf020297f

Kambur, M. Ş., Gündoğdu, M. (2020) Kivi Meyvelerinin Olgunlaşma Evrelerine Göre Fenolik Bileşik İçeriklerindeki Dağılım. UTYHBD, 6(2):194-201 https://doi.org/10.24180/ijaws.740571

Kesen, S. (2020) Characterization of aroma and aroma-active compounds of Turkish turmeric (Curcuma longa) extract. J. Raw Mater. Process. Foods, 1:13-21.

Komes, D., Lovric, T., Kovacevic, G., Gajdos, K., Banavic, M. (2005) Trehalose improves flavour retention in dehydrated apricot puree. International J. Food Sci. Technol.,
40:425-435. https://doi.org/10.1111/j.13652621.2005.00967.x

Lintas, C., Adorisio, S., Cappelloni, M. (1991) Composition and nutritional evaulation of kiwifruit grown in Italy. New Zealand $J$. Crop and Hortic. Sci., 19:341-344. https://doi.org/10.1080/01140671.1991.10 422872

Priser, C., Etievant, P.X., Niclaus, S., Brun, O. (1997) Representative champagne wine extract for gas chromatography olfactometry analysis. J. Agric. Food Chem., 45:3511-3514. https://doi.org/10.1021/jf970123b

Riu-Aumatell, M., Castellari, M., LopezTamames, E., Galassi, S., Buxaderas, S. (2004) Characterization of volatile compounds of fruit juices and nectars by HS/SPME and GC/MS. Food Chem., 87:627-637.

https://doi.org/10.1016/j.foodchem.2003.1 2.033

Riu-Aumatell, M., Lopez-Tamames, E., Buxaderas, S. (2005) Assessment of the volatile composition of juices of apricot, peach, and pear according to two pectolytic treatments. J. Agric. Food Chem., 53:78377843. https://doi.org/10.1021/jf051397z

Schneider, R., Razungles, A., Augier, C., Baumes, R. (2001) Monoterpenic and norisoprenoidic glycoconjugates of vitis vinifera $1 . \mathrm{cv}$. melon $\mathrm{b}$. as precursors of odorants in muscadet wines. J. Chrom. A, 936:145-157.

https://doi.org/10.1016/s0021-

9673(01)01150-5

Sevindik, O., Guclu, G., Bombai, G., Rombolá, A. D., Kelebek, H., Selli, D. (2020) Volatile compounds of cvs Magliocco Canino and Dimrit grape seed oils. J. Raw Mater. Process. Foods, 1 (2):47-54.

Sonmezdag, A. S., Kelebek, H., \& Selli, S. (2018) Pistachio oil (Pistacia vera L. cv. Uzun): characterization of key odorants in a representative aromatic extract by GC-MSolfactometry and phenolic profile by LC- 


\section{Türkiye'nin Farklı İllerinde Yetiştirilen "Hayward" (A. Deliciosa Planch) Kivi Çeşidinin Serbest Aroma Bileşiklerinin Belirlenmesi}

ESI-MS/MS. Food Chem., 240:24-31. https://doi.org/10.1016/j.foodchem.2017.0 7.086

Şen, K. (2021) The influence of different commercial yeasts on aroma compounds of rosé wine produced from cv. Öküzgözü grape. J. Food Process Preserv., ,00:e15610.

https://doi.org/10.1111/jfpp.15610

Tang, C.S., Jennings, G. (1967) Volatile components of apricot. J. Agric. Food Chem., 15:24-28.

Tob, (1983) G1da maddeleri muayene ve analiz yöntemleri kitabı. Türkiye Cumhuriyeti Tarım ve Orman Bakanlığı Yayınları, https://kutuphane.tarimorman.gov.tr/vufind /Record/9110

Topi, D. (2020) Volatile and Chemical Compositions of Freshly Squeezed Sweet Lime (Citrus limetta) Juices. J. Raw Mater. Process. Foods, 1:22-27. https://doi.org/10.1021/jf60149a009

Tüik, (2021) Türkiye İstatistik Kurumu. https://data.tuik.gov.tr/Bulten/Index?p=Cro p-Production-2020-33737.

Tüik, (2002) Tarımsal yapı (üretim, fiyat, değer) T.C. Başbakanlık DİE Yayın No: 2614, Ankara.

Uçkun, O., \& Selli, S. (2017) Characterization of key aroma compounds in a representative aromatic extract from citrus and astragalus honey based on aroma extract dilution analyses. J. Food Measur. and Charac., 11(2):512-522.

https://doi.org/10.1007/s11694-016-9418-9

Uslu, N. A. (2006) Kivide budama ve sürgün gelişiminin meyve kalitesi ve verim üzerine kantitatif ve kalitatif etkileri. Ondokuz Mayıs Üniversitesi Fen Bilimleri Enstitüsü Bahçe Bitkileri Anabilim Dalı Doktora Tezi, Samsun.

Van Den Hool, H., Kratz, P.D., A. (1963) Generalization of the retention index system including linear temperature programmed gas-liquid partition chromatography. J. Chromatogr., 11:463471. https://doi.org/10.1016/S00219673(01)80947-X

Wan, X. M., Stevenson, R.J., Chen, X. D., Melton, L. D. (1999) Application of headspace solid-phase microextraction to volatile flavour profile development during storage and ripening of kiwifruit. Food Res. Int., 32:175-183.

https://doi.org/10.1016/S09639969(99)00074-5

Wang, M. Y., MacRae, E., Wohlers, W., Marsh K. (2011) Changes in volatile production and sensory quality of kiwifruit during fruit maturation in Actinidia deliciosa 'Hayward' and A. chinensis 'Hort16A'. Postharv. Bio. and Tech.,59:16-24. https://doi.org/10.1016/j.postharvbio.2010. 08.010

Zhao, N., Zhang, Y., Liu, D., Zhang, J., Qi1,Y., Xu, J., Wei, X., Fan, M. (2021) Free and bound volatile compounds in 'Hayward' and 'Hort16A' kiwifruit and their wines. Europ. Food Res. and Tech., 246:875-890. https://doi.org/10.1007/s00217-020-034529 